\title{
(6) OPEN ACCESS \\ Algorithms to guide ambulance clinicians in the management of emergencies in patients with implanted rotary left ventricular assist devices
}

\author{
Christopher T Bowles, ${ }^{1}$ Rachel Hards, ${ }^{1}$ Neil Wrightson, ${ }^{2}$ Paul Lincoln, ${ }^{3}$ Shishir Kore, ${ }^{4}$ \\ Laura Marley, ${ }_{1}^{5}$ Jonathan R Dalzell, ${ }^{6}$ Binu Raj, ${ }^{1}$ Tracey A Baker, ${ }^{1}$ Diane Goodwin, ${ }^{3}$ \\ Petra Carroll, ${ }^{1}$ Jane Pateman, ${ }^{7}$ John J M Black, ${ }^{8}$ Paul Kattenhorn, ${ }^{9}$ Mark Faulkner, ${ }^{10}$ \\ Jayan Parameshwar, ${ }^{3}$ Charles Butcher, ${ }_{1}^{1}$ Mark Mason, ${ }^{1}$ Alexander Rosenberg, ${ }_{1}{ }^{1}$ \\ Ian McGovern, Alexander Weymann, ${ }^{1}$ Carl Gwinnutt, ${ }^{11}$ Nicholas R Banner, ${ }^{1}$ \\ Stephan Schueler, ${ }^{2}$ Andre R Simon, ${ }^{1}$ David W Pitcher ${ }^{11}$
}

For numbered affiliations see end of article.

\section{Correspondence to} Dr Christopher T Bowles, Department of Cardiothoracic Transplantation and Mechanical Circulatory Support, Royal Brompton and Harefield NHS Foundation Trust, Harefield Hospital, London UB9 6JH, UK; c.bowles@rbht.nhs.uk

Received 5 July 2016 Revised 27 July 2017 Accepted 2 September 2017

\section{Linked}

- http://dx.doi.org/10.1136/ emermed-2015-204912

CrossMark

To cite: Bowles CT,

Hards R, Wrightson N,

et al. Emerg Med J

2017:34:842-849.

\section{ABSTRACT}

Advances in left ventricular assist device (LVAD) therapy have resulted in increasing numbers of adult LVAD recipients in the community. However, device failure, stroke, bleeding, LVAD thrombosis and systemic infection can be life-threatening emergencies. Currently, four LVAD systems are implanted in six UK transplant centres, each of which provides device-specific information to local emergency services. This has resulted in inconsistent availability and content of information with the risks of delayed or inappropriate decision-making. In order to improve patient safety, a consortium of UK healthcare professionals with expertise in LVADs developed universally applicable prehospital emergency algorithms. Guidance was framed as closely as possible on the standard ABCDE approach to the assessment of critically ill patients.

\section{INTRODUCTION}

Clinical trials have established the efficacy of left ventricular assist device (LVAD) therapy for advanced heart failure. ${ }^{1-4}$ Ongoing technological improvements and a growing mismatch between the demand for donor hearts for transplantation and their supply have resulted in a progressive increase in the number of patients receiving LVAD support in the UK. ${ }^{56}$ In January 2016, 207 adult patients were receiving LVAD therapy in the UK, $184(89 \%)$ as outpatients. ${ }^{i}$ These numbers are predicted to increase more rapidly following endorsement of LVAD use as destination therapy (LVAD therapy without planned heart transplantation) by the National Institute for Health and Care Excellence. $^{78}$

Four types of LVAD system are implanted in the six UK adult heart transplant centres, in Birmingham, Glasgow, Harefield (London), Manchester, Newcastle and Papworth (Cambridge): Medtronic Inc. HVAD, St Jude Medical Inc. Heartmate II with original controller or with pocket controller and Heartmate 3 . All contain a rotating

${ }^{\mathrm{i}}$ Audit data provided by CB, NW, PL, SK, LM and JD (January 2016).

\section{Key messages}

What is already known on this subject?

- There are increasing numbers of left ventricular assist device (LVAD) recipients in the community.

- These patients are vulnerable to device failure, stroke, bleeding, systemic infection and LVAD thrombosis, all of which can be life-threatening for the patient and a significant challenge for ambulance clinicians.

- Centres which implant LVADs provide devicespecific information to local emergency services when a patient leaves hospital, but this has resulted in inconsistent availability and content of information, risking delayed or inappropriate decision-making in an emergency.

What this study adds

- If distributed to and used by ambulance clinicians in the UK, the algorithms presented here can improve safety for adult LVAD recipients who experience an out-of-hospital emergency.

impeller that propels blood from the left ventricle to the aorta. ${ }^{9}$ LVAD recipients are normally ambulatory adult outpatients who, despite subnormal exercise tolerance, ${ }^{10}$ travel extensively within the UK. However, LVAD failure is a life-threatening emergency. ${ }^{11-15}$ This dependency arises for two reasons: (1) without support, the dysfunctional left ventricle may not be able to generate an adequate cardiac output to sustain life and (2) the device contains no valves, so when an LVAD fails, there is retrograde blood flow through the device during ventricular diastole limiting systemic perfusion. ${ }^{16}$ Moreover, LVAD outpatients are vulnerable to other complications, ${ }^{17}{ }^{18}$ particularly stroke, ${ }^{19}$ bleeding, ${ }^{20} 21$ systemic infection ${ }^{22} 23$ and LVAD thrombosis,. 2425 The modus operandi and troubleshooting of LVADs is reviewed in the current issue of this journal. ${ }^{26}$ Individual VAD centres have developed local policies to support discharge of their LVAD recipients 
- Emergency algorithms should, as far as practicable, concord with the conventional ABCDE approach to the assessment of a critically ill person, with which ambulance clinicians are familiar.

- It should be possible to apply the algorithms to both historical "real life" emergency scenarios and hypothetical emergencies.

- Information should be presented in a format which can be included in the emergency algorithms booklet carried by UK ambulance clinicians, and/or provided as a Smartphone App, and/or carried by the LVAD patient.

- There should be no assumption of prior exposure to/knowledge of LVADs.

- The importance of establishing communication with VAD co-ordinators, preferably at an early stage, should be emphasised.

- The atypical effects of LVAD therapy on patient physiology should be highlighted and the resultant difficulty this can create when attempting to monitor certain vital signs.

- Sufficient information should be provided to allow identification of each LVAD system, and disconnection and reconnection of the external components.

- The need to adapt procedures for cardiopulmonary resuscitation (CPR), defibrillation and DC cardioversion, according to the clinical status of the patient, should be highlighted.

- Relatives/caregivers who have previously received structured LVAD training by the VAD centre should be encouraged to assist in LVAD-related emergencies and ambulance transfer to hospital.

- The need to transport the patient's emergency LVAD equipment with them during transfer to hospital should be highlighted.

- Ambulance clinicians should be given access to relevant training resources.

Figure 1 Guiding principles identified for the development of emergency algorithms. LVAD, left ventricular assist device; DC, direct current.

into the community, including provision of information for ambulance clinicians and EDs. ${ }^{27}$ However, there is no universal LVAD-specific training standard for emergency medical services in either the USA or Europe and this has resulted in inconsistent availability and content of information, with attendant risks of delayed or inappropriate decision-making. ${ }^{28-30}$ The aim of this initiative was to develop emergency algorithms, applicable to all current LVAD systems, for national distribution to ambulance clinicians.

\section{METHODS}

A consortium of UK healthcare professionals-VAD coordinators, heart failure and VAD cardiologists, cardiac electrophysiologists, cardiothoracic surgeons with expertise in VADs and transplantation, cardiothoracic intensivists, trauma consultants, resuscitation practitioners, senior paramedics, medical directors of UK ambulance services and clinicians from the Resuscitation Council (UK) - contributed to the initiative. Discussion was guided by published LVAD emergency guidance, ${ }^{31}$ including web-based information, case reports and anecdotal UK experience. The guiding principles identified are shown in figure 1.

\section{Preparing for a future emergency at hospital discharge}

We have previously recommended that, at the time an LVAD patient is discharged from the hospital, local emergency services and emergency departments (EDs) are notified and offered information and training to support any response to an LVAD emergency, ${ }^{27}$ including the VAD centre 24/7 emergency contact telephone number, the patient's address, home telephone number and key medical information. This is referred to as the Patient Specific Protocol (PSP) which should be updated to reflect significant changes in clinical status, for example, heart transplantation and consequent LVAD removal. In the event of an emergency call from the patient's home, relevant information can thereby be made available to ambulance clinicians prior to patient contact. Discussion revealed anecdotal evidence that PSPs have allowed advance contact with UK VAD centres with attendant benefits, that is, the provision of relevant recent medical history and telephone guidance to ambulance clinicians by the VAD coordinator during emergency treatment. Establishing advance contact with the
VAD centre following notification of an emergency, provided it does not result in delayed treatment, is recommended (see Algorithm 1).

\section{Elements of the emergency algorithms}

It was not feasible to present all the information required on a single page while maintaining legibility. Instead, three sequential LVAD-specific algorithms were developed, as follows:

1. Initial assessment of the LVAD patient (including airway and breathing stages)

2. LVAD troubleshooting

3. Ensuring adequate circulation to sustain life.

These algorithms are presented as figures 2-4, respectively. Also provided are illustrations to allow identification of the LVAD system and provide instructions on disconnection and reconnection of the external components; diagrams showing the external components of the Medtronic HVAD, St Jude Heartmate II (original version), Heartmate II (pocket controller version) and the Heartmate three are presented as online supplementary figures $1-4$, respectively.

\section{Initial assessment of the LVAD patient (Algorithm 1)}

Information

The algorithm encourages obtaining early information whenever possible-from the PSP, by contacting the VAD centre and from the patient, their family or other bystanders.

Important note: These algorithms are intended only for use with LVAD recipients who have experienced sudden clinical deterioration. For clinically compromised LVAD recipients, where the LVAD has been non-functional for more than a few minutes, restarting the LVAD carries a theoretical risk of release of thrombus from the LVAD and embolic stroke. However, this risk may be offset by bidirectional blood flow through the non-functional $\operatorname{LVAD}^{16}$ and systemic anticoagulation. In a patient who is critically ill or in circulatory arrest, the balance of risk and benefit favours restarting a non-functioning LVAD. If LVAD non-function is suspected in a patient who is not severely compromised, immediate advice should be sought from the VAD centre. 
Initial Assessment of the Left Ventricular Assist Device (LVAD) Patient : Algorithm 1

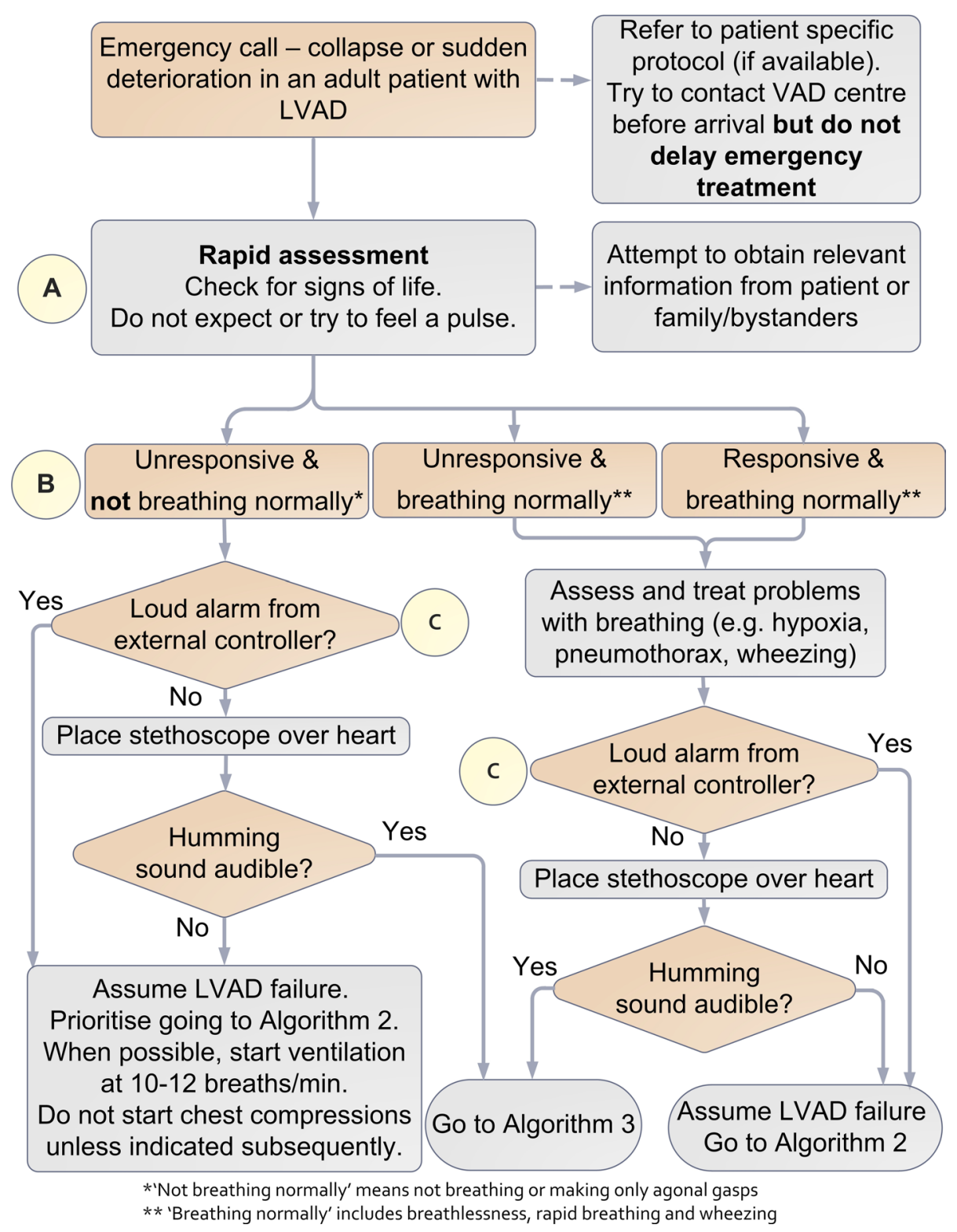

Figure 2 Initial assessment of the left ventricular assist device (LVAD) patient (Algorithm 1).

Initial assessment

Airway and breathing

This starts with a rapid assessment of the patient's responsiveness and breathing. In an unresponsive patient who is not breathing normally despite an open airway, that is, not breathing or giving only infrequent 'agonal' gasps (the features usually used to identify cardiac arrest ${ }^{32}$ ), ambulance clinicians should consider that a likely cause is that the LVAD has stopped and should proceed to the assessment of circulation. In the patient who is breathing normally, administration of oxygen and assessment to identify other respiratory conditions should follow standard Advanced Life Support guidelines. ${ }^{33}$

\section{Circulation}

This part of the assessment starts by determining if the LVAD is running. Unresponsiveness and absence of normal breathing usually implies circulatory arrest. In an LVAD recipient, sudden failure of the LVAD is the cause most likely to be corrected by prompt, appropriate intervention.

Sudden LVAD failure does not always cause circulatory arrest, so in an LVAD patient who is very ill but breathing, it is still important to check at this stage whether the LVAD is running. Clinicians should minimise delay by avoiding futile repeated attempts to palpate a pulse and record the arterial BP and oxygen saturation as these may be difficult or impossible to detect in compromised LVAD recipients (see Further assessment of circulation section for more details).

A loud alarm coming from the controller is likely to indicate a stopped LVAD, unless the display shows another explanation. If no alarm is sounding, LVAD failure is still a possibility (due to alarm battery depletion or alarm failure), so a stethoscope should be placed over the apex of the heart to listen for a humming 


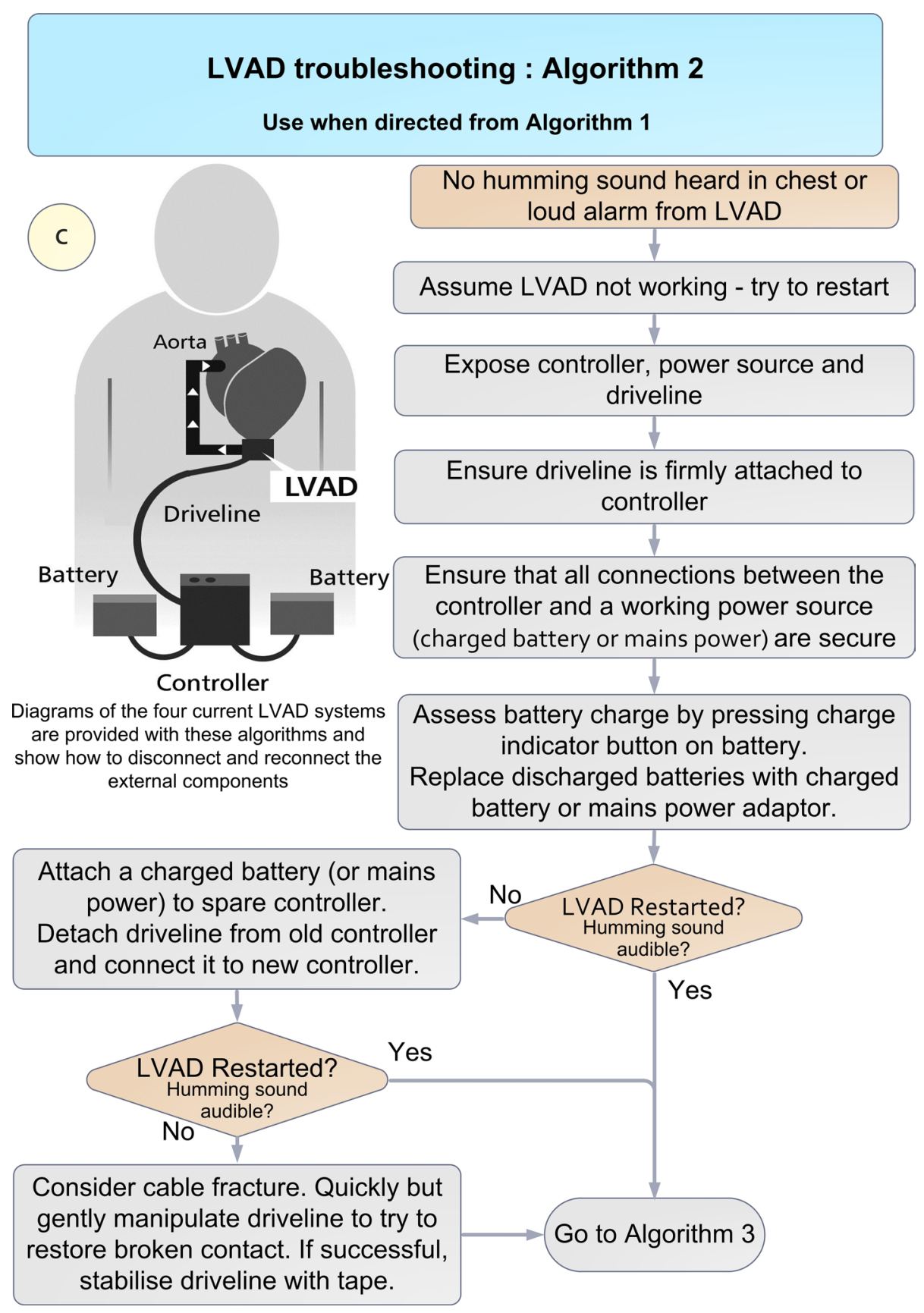

Figure 3 Left ventricular assist device (LVAD) troubleshooting (Algorithm 2).

sound. Absence of a humming sound indicates that the LVAD is not working. If a loud alarm is sounding, (with no other cause shown) or the pump is inaudible via stethoscope, the clinician is directed to Algorithm 2 (LVAD troubleshooting). If the LVAD is running normally (no alarm and audible hum via stethoscope), they are directed to Algorithm 3 (ensuring adequate circulation to sustain life).

\section{LVAD troubleshooting (Algorithm 2)}

If the LVAD has stopped, the most effective resuscitation manoeuvre is to restart it without delay. Operation of the LVAD is dependent on:

1. secure connection of an external controller to the percutaneous cable (driveline) of the implanted blood pump, AND
2. the supply of power to the external controller, either via a rechargeable battery or mains power (figure 3).

The percutaneous driveline usually exits the skin over the abdomen to the right of the umbilicus (see figure 3). All adult LVADs in use in the UK have two power connections to the controller, both of which are usually connected, although only a single working power source is needed for the LVAD to operate. This allows replacement of one power source, without interrupting LVAD operation. The controller and batteries may be carried in a bag, contained within pockets of the patient's clothing or belt-mounted.

If the LVAD is not running, first, check the external components of the LVAD. The clinician should open the LVAD bag containing the controller and batteries to expose the contents, and check that all connections to the controller are fully engaged 


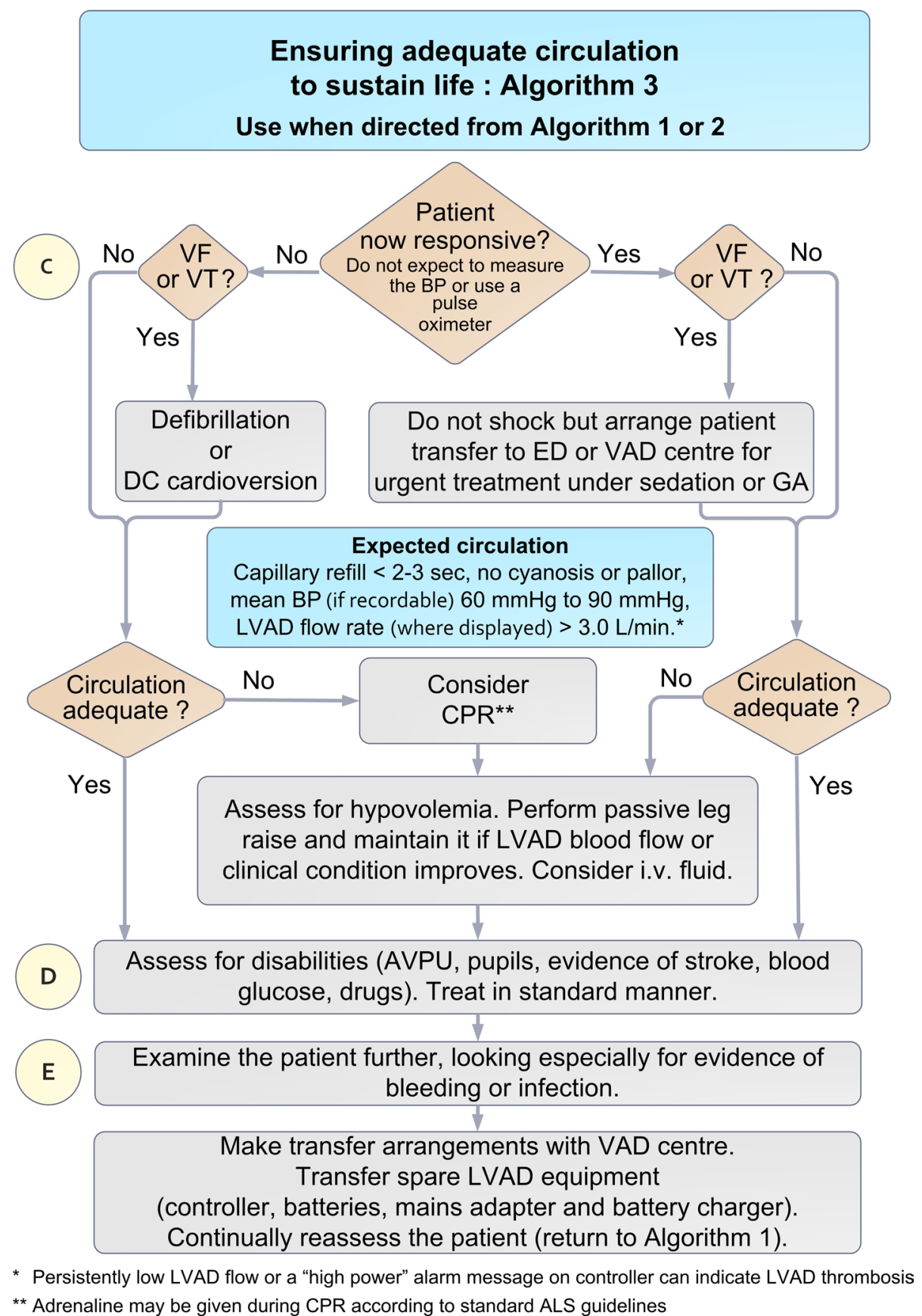

Figure 4 Ensuring adequate circulation to sustain life (Algorithm 3). CPR, cardiopulmonary resuscitation; LVAD, left ventricular assist device; VF, ventricular fibrillation; VT, ventricular tachycardia.

and secure. Next, they should check the battery charge by pressing a button on the battery that illuminates a display similar to a fuel gauge. If the battery charge level is low, the power source must be changed. Depleted batteries should be replaced with charged ones or with a mains power supply. If a mains power supply is in use and potentially defective, the device should be switched to a charged battery.

If these measures fail to restart the LVAD, it is presumed that the controller is defective. The spare controller (carried by the patient at all times) should be connected to a charged battery (or mains power). Then, the driveline should be disconnected from the presumed-defective controller and connected to the replacement controller whereupon the LVAD should restart.

If these actions do not restart the LVAD, the possibility of cable fracture within the driveline causing loss of electrical continuity should be considered. If suspected, gentle manipulation of the driveline may restore LVAD operation, in which case, the driveline should be stabilised (using tape).

If the LVAD cannot be restarted, or in the unlikely event that an LVAD patient is found in an unconscious state with a non-functioning LVAD and no spare equipment, the clinician should proceed to Algorithm 3 and the VAD centre should be contacted using a telephone number located on:

a. an identification card or bracelet

b. an Immediate Action Notice-in an envelope in the bag with the controller in use

c. on the LVAD controller itself or

d. in an emergency bag carried separately by the patient.

Active LVAD audible alarms are often accompanied by warning messages displayed on the controller screen. Such 
messages either indicate an LVAD fault which may cause rapid clinical deterioration or may be indicative of a clinical problem causing LVAD parameters to fall outside the normal operating range. Alarm messages thus facilitate diagnosis of LVAD-related or medical issues and should be reported to the VAD centre coordinator who can provide appropriate advice. The exception to this is the Heartmate II operating with the original controller, which does not display a message.

\section{Ensuring adequate circulation to sustain life (Algorithm 3) Overview}

Whether the LVAD was found to be running, or an attempt has been made to restart a non-functioning LVAD, the third algorithm should always be followed irrespective of clinical status and aims to ensure an adequate circulation. This includes checking the underlying cardiac rhythm, looking for signs of adequate perfusion and treating if necessary. Subsequently, the patient should be assessed for disabilities (eg, stroke, glucose, drugs) and examined for evidence of bleeding and infection. Finally, transfer arrangements are made in consultation with the VAD centre.

\section{Cardiac rhythm management}

Many LVAD recipients also have a cardiac resynchronisation therapy (CRT) pacemaker and, in some, their device incorporates an implantable cardiac defibrillator (ICD). Some have an ICD without CRT. An ICD would be expected to deliver a shock in the event of ventricular fibrillation (VF) or rapid ventricular tachycardia (VT). If a patient is unresponsive, and has VF or VT (with ICD not present or ineffective), immediate defibrillation (VF) or cardioversion (VT) is indicated. Some LVAD recipients without ICDs may be temporarily tolerant of what would normally be considered to be life-threatening ventricular arrhythmia (VF or VT) because LVAD operation is ECG independent and passive blood flow through the right heart and pulmonary circulation may sustain enough venous return to the LVAD to maintain systemic blood flow and consciousness. ${ }^{34}$ A responsive patient with VT or VF should be transported to the hospital for urgent treatment. If the patient becomes unresponsive during an episode of VT or VT prior to arrival at hospital, they should receive immediate defibrillation or cardioversion.

\section{Further assessment of circulation}

In addition to cardiac rhythm assessment and treatment (if indicated), ambulance clinicians should look for clinical signs of an adequate circulation (eg, capillary refill time less than $2 \mathrm{~s}$, absence of pallor/cyanosis). Emergency treatment must not be delayed while repeated attempts are made to measure arterial BP or pulse oximetry in LVAD patients; contemporary pumps produce continuous (non-pulsatile) blood flow, resulting in an attenuated arterial pulse pressure which typically renders ineffective usual sphygmomanometry ${ }^{35}$ and pulse oximetry. ${ }^{30} 31$ If arterial BP can be recorded, hypotension is a normal finding in LVAD recipients; a mean arterial BP between 60 and $90 \mathrm{~mm} \mathrm{Hg}$ would be considered acceptable. ${ }^{3637}$ Of the LVAD systems currently in use in the UK, all except the St Jude Medical Inc. HeartMate II-Original Controller (see online supplementary figure 2) can display LVAD blood flow rate. Normally, the Medtronic HVAD (online supplementary figure 1) displays the flow rate continuously on the controller screen unless an alarm message is displayed, in which case the flow can be displayed by pressing the button adjacent to the display marked with an arrow. The St Jude Medical Inc. HeartMate II-Pocket Controller (Online supplementary file 3) and HeartMate 3 (online supplementary figure 4) display LVAD flow rate if the controller button with a square symbol is depressed twice. In adults, flow is normally in the range of $3.5-6.5 \mathrm{~L} / \mathrm{min}$, and flow persistently less than $3.0 \mathrm{~L} / \mathrm{min}$ should be regarded as critically low. In an LVAD patient who is unresponsive, not breathing normally and has evidence of inadequate circulation (despite a running LVAD or all attempts to restart it), cardiopulmonary resuscitation (CPR) should be considered.

\section{CPR in LVAD recipients}

There is controversy as to whether chest compressions (CCs) should be applied to LVAD recipients. The controversy centres on safety, efficacy and when to start CCs. Resolution of these issues has been hampered by absence of high-quality evidence and insufficient detail to draw conclusions from published case reports. Foremost concerns arise because of perceived risks of LVAD cannula dislodgment or anastomotic rupture. Although LVAD manufacturers warn of these dangers, risks may have been overestimated. ${ }^{38}$ A recent questionnaire of 148 members of the International Society of Heart and Lung Transplantation (71\% from the USA) revealed that 28\% would instruct emergency medical services to deliver CCs. ${ }^{28}$ Forty-one per cent of respondents reported that LVAD recipients had received CCs in their institution with only one (1.7\%) reporting that this had resulted in cannula dislodgement contributing to death. Eleven per cent of respondents said that they would sanction CCs after a predefined period following LVAD implantation (range 10-30 days), that is, following initial postoperative healing, when the perceived risk of dislodgement/rupture is reduced. Thirty-two per cent of respondents said they would sanction CCs in outpatients. There is limited published evidence of a low risk of cannula/anastomosis rupture from CCs after 50 days of LVAD support. ${ }^{29} 38$

Evidence of CC efficacy in the presence of an LVAD is tenuous. Unsurprisingly, long periods of CC were associated with poor outcome. Short periods of CCs appeared to be associated with favourable outcomes, in keeping with a low risk of harm to an LVAD patient receiving CPR briefly, provided definitive treatment of the cause of circulatory arrest is not delayed. ${ }^{38}$

It is unclear whether CCs confer benefit if they are implemented prior to trying to restart an LVAD. It is reasonable to conclude that the balance of risks favours delivery of high-quality CCs by ambulance clinicians to LVAD recipients with out-of-hospital circulatory arrest either if attempts to restart an LVAD have failed or as a temporising measure until definitive intervention is possible, for example, while searching for missing emergency LVAD equipment to restart a LVAD which is not running.

Patients receiving CPR should have ECG monitoring in standard fashion; those with recurrent VF or VT should receive immediate defibrillation. Epinephrine may be given during CPR according to standard ALS guidelines.

\section{Assessing for hypovolaemia}

Hypovolaemia can reduce LVAD flow to critical levels. If this is the case, CPR should be commenced prior to the assessment of hypovolaemia. Otherwise, hypovolaemia can be assessed and treated without CPR. Hypovolaemia may be recognised by the display showing low LVAD flow $(<3 \mathrm{~L} / \mathrm{min})$, with or without an audible alarm. Risk factors for hypovolaemia include a history of bleeding (notably gastrointestinal). When hypovolaemia is suspected, intravenous fluid should be given. Sustained passive elevation of the legs may provide a transient increase in venous return and help to maintain perfusion until the fluid has been administered. ${ }^{3940}$ If passive leg raising is followed by a transient 
increase in flow rate through the LVAD (sometimes for less than a minute), this supports the likely need for intravenous fluid. Positive responses to fluid administration include an increase in the displayed LVAD flow rate and clinical evidence of improved circulation. However, administration of excessive fluid can potentiate right heart failure; further advice can be provided by the VAD centre.

\section{Pump thrombosis}

LVAD thrombosis is a serious complication which may be accompanied by signs of an inadequate circulation and is usually characterised in one of two ways: (1) Persistently low LVAD flow despite euvolaemia; this can be due to partial occlusion of the LVAD blood path by thrombus. (2) Thrombus formation at the impeller/pump-housing interface causes increased friction on the impeller, resulting in excessive LVAD power consumption that may be intermittent or continuous and may activate a high-LVAD power alarm. Impinging thrombus causing excessive power consumption can lead to overestimation of pump flow.

If signs of an inadequate circulation persist despite appropriate treatment, pump thrombosis should be suspected and the situation discussed with the VAD centre.

\section{Disability and exposure}

If the circulation has been stabilised or was stable from the outset, potential causes of clinical compromise (eg, haemorrhagic or embolic stroke, bleeding, sepsis or drug therapy) should be considered using the 'Disability' and 'Exposure' components of the ABCDE approach.

\section{Planning transfer to hospital}

Whether a patient should be transported to the local ED or to the VAD centre should be determined by dialogue with the VAD centre. This decision will depend on the patient's clinical condition and logistic considerations. Appropriately trained caregivers should be encouraged to accompany the patient during ambulance transfer to hospital. It is of paramount importance that all emergency LVAD equipment (including the spare controller, rechargeable batteries, mains power adapter and battery charger) is transferred to hospital with the patient, as sustained LVAD function is dependent on the availability of these components. It is important to monitor the patient continuously during transfer as clinical deterioration can be sudden.

\section{DISCUSSION}

The increasing prevalence of LVAD use, ${ }^{5}$ the high proportion of all LVAD recipients in the community and their vulnerability to life-threatening complications ${ }^{11-15} 21-25$ underscore the importance of making appropriate resuscitation guidance widely available to ambulance clinicians. Although there have been improvements in the training of emergency medical service providers, the information provided and training methods remained inconsistent. $^{28}$

The provision of effective training of healthcare providers in prehospital management of LVAD-related emergencies is a substantial challenge. The use of multiple LVAD designs has rendered comprehensive, device-specific training of ambulance clinicians impractical. To address these limitations, the strategy adopted here was to develop emergency algorithms generalisable to different LVAD designs and to avoid potentially counterproductive complexity. Emphasis has been placed on establishing communication with the implanting VAD centre and provision of readily accessible resources for use in an emergency. This initiative has the support of the UK Joint Royal Colleges Ambulance Liaison Committee. Further work is needed to implement the proposals fully and assess their impact.

\section{Advance statements, living wills, advance decisions to refuse treatment and do-not-attempt-CPR decisions}

There is evidence of sporadic initiation of advance statements (living wills) or Advance Decisions to Refuse Treatment (England and Wales), (ADRTs), in UK LVAD outpatients. More frequently, do-not-attempt-CPR decisions have been recorded by healthcare professionals for LVAD inpatients typically with participation of the patient in the decision-making process if they have the capacity or otherwise their family or authorised representative. ${ }^{41}$ The increasing international use of LVADs for destination therapy in more elderly patients has focused debate on end-oflife care planning, with more patients preferring to die in their home rather than in hospital. ${ }^{42}$ The consortium recommends that the existence and location of advance statements, ADRTs and recommendations about CPR and/or other life-sustaining treatments should be recorded in the PSP. Unless there is a valid and applicable advance statement, ADRT or other recommendations warranting a different response in a community setting, the measures recommended in these algorithms may be assumed to be appropriate for any critically ill LVAD recipient.

\section{Limitations}

The information provided is neither comprehensive nor directly applicable to partial-support LVADs (where the left ventricle continues to contribute to systemic blood flow), biventricular assist devices, total artificial hearts (where the heart is replaced with two prosthetic ventricles), to certain LVAD designs used in younger children or to alternative forms of mechanical circulatory support. However, in the UK, such treatments are currently very rare, and so are unlikely to be encountered by ambulance clinicians.

\section{CONCLUSION}

It is anticipated that the distribution of these emergency algorithms to ambulance clinicians will increase the probability that out-of-hospital emergencies in LVAD recipients will be managed appropriately. The efficacy of this initiative should be determined by means of a national audit.

\section{Author affiliations}

'Department of Cardiothoracic Transplantation and Mechanical Circulatory Support, Royal Brompton and Harefield NHS Foundation Trust, London, UK

${ }^{2}$ Department of Cardiothoracic Transplantation, Freeman Hospital, Newcastle upon Tyne, UK

${ }^{3}$ Department of Cardiothoracic Transplantation, Papworth Hospital NHS Foundation Trust, Cambridge, UK

${ }^{4}$ Department of Cardiothoracic Transplantation, Wythenshawe Hospital, University

Hospital of South Manchester NHS Foundation Trust, Manchester, UK

${ }^{5}$ Department of Cardiothoracic Transplantation, Queen Elizabeth Hospital

Birmingham, Birmingham, UK

${ }^{6}$ Scottish Advanced Heart Failure Service, Golden Jubilee National Hospital, Glasgow, UK

${ }^{7}$ Anaesthetic Department, Royal Sussex County Hospital, Brighton, UK

${ }^{8}$ Clinical Directorate, South Central Ambulance Service Foundation Trust, Oxfordshire, UK

${ }^{9}$ East of England Ambulance Service Headquarters, Whiting Way, Melbourn, Cambs.,

SG8 6EN., East of England Ambulance Service Headquarters, Melbourn, Cambs, UK

${ }^{10}$ London Ambulance Service, Medical Directorate Office, London, UK

${ }^{11}$ Resuscitation Council, London, UK

Acknowledgements The consortium is indebted to Mr Garry Johnson, Medtronic for agreeing to provide financial support for this initiative, to Mr Martin Smith of

Origin8Design and Anne Wadmore for illustration services and to Rhiannon Taylor, 
Senior Statistician, National Heart Service Blood and Transplant, UK for LVAD population statistics.

Contributors CTB chaired the consortium and is guarantor of the manuscript's content. RH, NW, PL, SK, LM and JD and MF provided audit data. CTB, BR, JB, CB, $M M, A R$, IMG, CG, NRB, SS, AS and DP contributed to algorithm development. TB, $D G, P C, J P, P K$ made contributions during the meetings. All authors contributed to the development of the manuscript and approved the final version.

Competing interests $\mathrm{RH}$ and AS have had remunerated consultancy agreements with Medtronic which provided funding for this initiative.

Provenance and peer review Not commissioned; externally peer reviewed.

Open Access This is an Open Access article distributed in accordance with the Creative Commons Attribution Non Commercial (CC BY-NC 4.0) license, which permits others to distribute, remix, adapt, build upon this work non-commercially, and license their derivative works on different terms, provided the original work is properly cited and the use is non-commercial. See: http://creativecommons.org/ licenses/by-nc/4.0/

(c) Article author(s) (or their employer(s) unless otherwise stated in the text of the article) 2017. All rights reserved. No commercial use is permitted unless otherwise expressly granted.

\section{REFERENCES}

1 Slaughter MS, Rogers JG, Milano CA, et al. Advanced heart failure treated with continuous-flow left ventricular assist device. N Engl J Med 2009;361:2241-51.

2 Aaronson KD, Slaughter MS, Miller LW, et al. Use of an intrapericardial, continuousflow, centrifugal pump in patients awaiting heart transplantation. Circulation 2012;125:3191-200

3 Miller LW, Pagani FD, Russell SD, et al. Use of a continuous-flow device in patients awaiting heart transplantation. N Engl J Med 2007;357:885-96.

4 Birks EJ, Tansley PD, Hardy J, et al. Left ventricular assist device and drug therapy for the reversal of heart failure. N Engl J Med 2006;355:1873-84.

5 Emin A, Rogers CA, Parameshwar J, et al. Trends in long-term mechanical circulatory support for advanced heart failure in the UK. Eur J Heart Fail 2013;15:1185-93.

6 National Health Service. 2015. Annual report on ventricular assist devices. UK: National Health Service Blood and Transplant.

7 Slaughter MS, Meyer AL, Birks EJ. Destination therapy with left ventricular assist devices: patient selection and outcomes. Curr Opin Cardiol 2011;26:232-6.

8 National Institute for Clinical Excellence. Implantation of a left ventricular assist device for destination therapy in people ineligible for heart transplantation. UK: National Institute for Clinical Excellence, 2015. Report No: IPG 516.

9 Harris P, Kuppurao L. Ventricular assist devices. Continuing Education in Anaesthesia, Critical Care \& Pain 2012;12:145-51.

10 Jakovljevic DG, McDiarmid A, Hallsworth K, et al. Effect of left ventricular assist device implantation and heart transplantation on habitual physical activity and quality of life. Am J Cardiol 2014;114:88-93.

11 Bischof D, Graves K, Genoni M, et al. Fatal disconnection of a ventricular assist device in an out-of-hospital setting. Emerg Med J 2012;29:247-8.

12 Cubillo El, Weis RA, Ramakrishna H. Emergent reconnection of a transected left ventricular assist device driveline. J Emerg Med 2014;47:546-51.

13 Schima H, Stoiber M, Schlöglhofer T, et al. Repair of left ventricular assist device driveline damage directly at the transcutaneous exit site. Artif Organs 2014;38:422-5.

14 Man survives after LVAD battery almost fails. J Emerg Med Serv 2010 http://www. jems.com/articles/2010/08/man-survives-after-lvad-batter-0.html (accessed Nov 2016).

15 Tigges-Limmer K, Schönbrodt M, Roefe D, et al. Suicide after ventricular assist device implantation. J Heart Lung Transplant 2010;29:692-4.

16 Noor MR, Ho CH, Parker $\mathrm{KH}$, et al. Investigation of the characteristics of Heartware HVAD and thoratec Heartmate II under steady and pulsatile flow conditions. Artif Organs 2016;40:549-60.

17 MacGowan GA, Schueler S. Right heart failure after left ventricular assist device implantation: early and late. Curr Opin Cardiol 2012;27:296-300.
18 Patil NP, Sabashnikov A, Mohite PN, et al. De novo aortic regurgitation after continuous-flow left ventricular assist device implantation. Ann Thorac Surg 2014;98:850-7.

19 Harvey L, Holley C, Roy SS, et al. Stroke after left ventricular assist device implantation: outcomes in the continuous-flow era. Ann Thorac Surg 2015;100:535-41.

20 Islam S, Cevik C, Madonna R, et al. Left ventricular assist devices and gastrointestinal bleeding: a narrative review of case reports and case series. Clin Cardiol 2013;36:190-200.

21 Bhat $P$, Nassif ME, Vader JM, et al. Epistaxis in patients with left ventricular assist devices - incidence, risk factors, and implications. J Heart Lung Transp/ 2014;33:S246.

22 Stulak JM, Davis ME, Haglund N, et al. Adverse events in contemporary continuousflow left ventricular assist devices: A multi-institutional comparison shows significant differences. J Thorac Cardiovasc Surg 2016:151:177-89.

23 Koval CE, Thuita L, Moazami N, et al. Evolution and impact of drive-line infection in a large cohort of continuous-flow ventricular assist device recipients. J Heart Lung Transp/ 2014;33:1164-72.

24 Starling RC, Moazami N, Silvestry SC, et al. Unexpected abrupt increase in left ventricular assist device thrombosis. N Engl J Med 2014;370:33-40.

25 Najjar SS, Slaughter MS, Pagani FD, et al. An analysis of pump thrombus events in patients in the HeartWare ADVANCE bridge to transplant and continued access protocol trial. J Heart Lung Transp/ 2014;33:23-34.

26 Vierecke J, Schweiger M, Feldman D, et al. Emergency procedures for patients with a continuous flow left ventricular assist device. Emerg Med J 2016: Nov 15 (Epub ahead of print).

27 Bowles C. Left ventricular assist devices in the community. Perfusion 2000;15:373-4.

28 Powell KR, Flattery MP, Cei LF, et al. Pre-hospital care for VAD patients: where are the gaps? J Heart Lung Transp/ 2015;34:S23.

29 Shah KB, Cei LF, Pinney SP, et al. Emergency care for patients with continuous flow left ventricular assist devices. J Heart Lung Transp/ 2014;33:S220-1.

30 Bramstedt KA, Simeon DJ. The challenges of responding to "high-tech" cardiac implant patients in crisis. Prehosp Emerg Care 2002;6:425-32.

31 Moazami N. Patients with a ventricular assist device need special considerations. J Emerg Med Serv 2012 http://www.jems.com/articles/print/volume-37/issue-2/patientcare/patients-ventricular-assist-device-need.html.

32 Resuscitation Council. Resuscitation Guidelines 2015. Adult basic life support and automated external defibrillation. www.resus.org.uk/resuscitation-guidelines/adultbasic-life-support-and-automated-external-defibrillation (accessed Nov 2016).

33 Resuscitation Council. Resuscitation Guidelines 2015. Adult advanced life support. www.resus.org.uk/resuscitation-guidelines/adult-advanced-life-support (accessed Nov 2016).

34 Busch MC, Haap M, Kristen A, et al. Asymptomatic sustained ventricular fibrillation in a patient with left ventricular assist device. Ann Emerg Med 2011;57:25-8.

35 Bennett MK, Roberts CA, Dordunoo D, et al. Ideal methodology to assess systemic blood pressure in patients with continuous-flow left ventricular assist devices. J Heart Lung Transp/ 2010;29:593-4.

36 Lanier GM, Orlanes K, Hayashi Y, et al. Validity and reliability of a novel slow cuff-deflation system for noninvasive blood pressure monitoring in patients with continuous-flow left ventricular assist device. Circ Heart Fail 2013;6:1005-12.

37 Slaughter MS, Pagani FD, Rogers JG, et al. Clinical management of continuous-flow left ventricular assist devices in advanced heart failure. J Heart Lung Transplant 2010;29:\$1-39.

38 Shinar Z, Bellezzo J, Stahovich M, et al. Chest compressions may be safe in arresting patients with left ventricular assist devices (LVADs). Resuscitation 2014;85:702-4.

39 Muthiah K, Gupta S, Otton J, et al. Body position and activity, but not heart rate affect pump flows in patients with continuous-flow left ventricular assist devices. J Am Coll Cardiol: Heart Fail 2014;2:323-30.

40 Monnet $X$, Teboul JL. Passive leg raising: five rules, not a drop of fluid!. Crit Care 2015;19:18.

41 Maclver J, Ross HJ. Withdrawal of ventricular assist device support. J Palliat Care 2005;21:151-6.

42 Brush S, Budge D, Alharethi R, et al. End-of-life decision making and implementation in recipients of a destination left ventricular assist device. $J$ Heart Lung Transplant 2010;29:1337-41. 